\title{
DynamicSainT
}

Jilid. IV No. 2., Oktober 2019

\section{PENGARUH PENAMBAHAN LIMBAH ALUMINIUM KEMASAN MINUMAN TERHADAP KARAKTERISTIK LAPISAN ASPAL BETON}

\author{
Parea Rusan Rangan ${ }^{1 *}$, Jacob Bokko², Marnet Lobo'3 \\ 1,2,3) Program Studi Teknik Sipil, Fakultas Teknik, Universitas Kristen Indonesia Toraja. \\ Jl. Nusantara No. 12,Makale, Tana Toraja, Sulawesi Selatan
}

\begin{abstract}
ABSTRAK
Perkerasan jalan raya adalah merupakan bagian dari konstruksi jalan raya yang diperkeras dengan lapis konstruksi tertentu, yang memiliki ketebalan, kekuatan, dan kekakuan, serta kestabilan tertentu agar mampu menyalurkan beban lalulintas diatasnya ketanah dasar secara aman. Tujuan dari penelitian ini adalah untuk mengetahui pengaruh penambahan limbah aluminium terhadap karakteristik lapisan aspal beton. Penelitian dilakukan di laboratorium Teknik Sipil UKI Toraja dengan menggunakan metode pengujian Marshall berdasarkan standar Bina Marga tahun 2010 revisi 3 mengenai Campuran Aspal Panas. Hasil yang diperoleh dari pengujian untuk mendapatkan Kadar Aspal Optimun (KAO) yaitu nilai VIM 4,71\%, nilai VMA 15,88\%, nilai VFB 70,46\%, nilai stabilitas 943,14 kg, nilai Flow 3,3 mm dan Marshall Quotient sebesar 283,49 kg/mm sedangkan pada penambahan limbah aluminium pada variasi KAO nilai VIM, VMA, VFB memenuhi standar spesifikasi tetapi pada pengujian stabilitas dan flow tidak memenuhi Standar
\end{abstract}

Kata Kunci: AC-WC, Aluminium, Karakteristik

\section{PENDAHULUAN}

\subsection{Latar Belakang}

Jalan raya merupakan tulang punggung suatu kawasan dalam menyalurkan beban penumpang barang dan jasa, selain itu jalan juga merupakan bagian dari infrastruktur guna membuka daerah yang terisolir; untuk pertahanan nasional dan untuk pengembangan tingkat sosial; ekonomi dan budaya dari suatu daerah, sehingga konstruksi badan jalan harus kuat dan tahan terhadap beban lalu lintas yang berlalu lalang setiap hari.

Limbah aluminium banyak yang terbuang dan tidak dimanfaatkan, hal ini akan menambah beban bagi pemerintah dalam mendaur ulang sampah aluminium, pada penelitian ini, akan digunakan sampah aluminium sebagai bahan tambah pada campuran beton aspal. Penggunaan aluminium sebagai alternatif bahan tambah, diharapkan dapat meningkatkan kualitas perkerasan aspal beton dan mengetahui sifat- sifat campuran melalui karakteristik Marshall campuran tersebut yang meliputi kerapatan campuran (density), nilai persentase rongga dalam campuran (Void In The Mix), nilai persentase rongga dalam campuran yang terisi aspal (Void Filled With Asphalt), nilai stabilitas, kelelehan (Flow), hasil bagi Marshall (Marshall Quotient). Berapa besar tambahan kadar aluminium agar dapat mencapai kadar aspal optimum.

\subsection{Tujuan Penelitian}

Adapun yang menjadi tujuan dari penelitian ini adalah mengetahui pengaruh penambahan limbah aluminium kemasan minuman terhadap karakteristik lapisan aspal beton.

\subsection{Manfaat Penelitian}

Manfaat yang diharapkan penelitian ini untuk mahasiswa adalah dapat menambah wawasan dalam mengelolah limbah aluminium kemasan minuman sebagai campuran aspal, sedangkan manfaat untuk masyarakat yaitu mengurangi dampak pencemaran lingkungan akibat limbah 


\section{DynamicSainT}

Jilid. IV No. 2., Oktober 2019

aluminium, serta manfaat untuk pemerintah yaitu meringankan beban pemerintah dalam penangulangan limbah aluminum.

\subsection{Batasan Penelitian}

Metode yang digunakan dalam penelitian ini adalah kajian eksperimental di Laboratorium Teknik Sipil Universitas Kristen Indonesia Toraja, KabupatenToraja Utara. Sebelum melakukan penelitian, maka perlu adanya perencanaan terhadap cara atau tahap-tahap dalam penelitian. Adapun tahap tahap pelaksanaan dalam penelitian sebagai berikut :

a. Studi kepustakaan, mencari dan mempelajari data-data yang berkaitan dengan pemanfaatan limbah alumunium sebagai bahan tambah pada lapisan aspal dingin dari buku-buku literatur serta browsing internet.

b. Pengujian di laboratorium, dimulai dengan tahap persiapan alat dan bahan, tahap pengujian bahan, tahap pembuatan benda uji, tahap perawatan benda uji, tahap pengujian marshall benda uji, dan tahap pengolahan data.

\section{KAJIAN PUSTAKA}

\subsection{Aluminium ( Kemasan Minuman )}

Alumunium adalah salah satu jenis logam yang terdapat pada kerak bumi. Meski jumlahnya cukup banyak, alumunium jarang ditemukan dalam bentuk aslinya. Sebagian besar alumunium digunakan dalam proses industri diekstraksi melalui proses bernama Hell-Heroult. Dalam proses ini aluminium aluminiumoksida dihilangkan dari cryilte yang telah dilelehkan kemudian dialiri listrik untuk mengubahnya menjadi aluminium alami. Karena kelimpahan, biaya rendah, dan kualitas yang berguna, aluminium digunakan dalam ribuan produk termasuk pada kemasan berbagai jenis minuman.Limbah kaleng adalah limbah yang tidak bisa diurai secara alami atau proses biologi, limbah kaleng ini termasuk limbah anorganik. Kaleng adalah lembaran baja yang disalut timah. Bagi orang awam, kaleng sering diartikan sebagai tempat penyimpanan atau wadah yang terbuat dari logam dan digunakan untuk mengemas makanan, minuman atau produk lain. Dalam pengertian ini, kaleng juga termasuk wadah yang terbuat dari aluminium dan campuran logam lainnya. Terkadang lapisan ini dilapisi lagi oleh lapisan bukan metal yaitu untuk mencegah reaksi dengan makanan ataupun minuman di dalamnya. Kelebihan menonjol dari kemasan ini adalah bisa dilakukannya proses sterilisasi, sehingga makanan yang disimpan di dalamnya menjadi steril, tidak mudah rusak, dan awet. Dan pengertian dari baja adalah logam alloy yang komponen utamanya adalah besi (Fe), dengan karbon sebagai material pengalloy utama. Baja dengan peningkatan jumlah karbon dapat memperkeras dan memperkuat besi, tetapi juga lebih rapuh. Definisi klasik, baja adalah besi-karbon alloy dengan kadar karbon sampai 5,1 persen; ironisnya, alloy dengan kadar karbon lebih tinggi dari ini dikenal dengan besi (Fe). Definisi yang lebih baru, baja adalah alloy berdasar besi yang dapat dibentuk secara plastik. Pada kaleng, daya ketahanan timah terhadap korosi juga tidak sempurna, akan tetapi terhadap reaksi dengan makanan di dalamnya lebih lambat dibandingkan dengan baja kareng struktur pada logam tersebut.

Berkembangnya industri kemasan, kaleng merupakan salah satu wadah yang banyak dipergunakan oleh industri makanan dan minuman. Praktis, mudah dibawa, dan menarik dengan aneka lukisan atau gambar pada dinding luar kaleng. Meningkatnya penggunaan kaleng sebagai wadah makanan atau minuman memberikan masalah lingkungan yang menjadi perhatian bersama. Kalengkaleng tersebut menjadi salah satu bahan bahan pencemar yang mengganggu lingkungan. Sampah yang menimbulkan karat dan akan mengganggu terhadap kesuburan tanah. Sampah padat yang lama mengalami proses penguraian dalam tanah.

Dalam perkembangannya sampah kaleng menjadi bahan yang dicari para 


\section{DynamicSainT}

Jilid. IV No. 2., Oktober 2019

pemulung barang bekas untuk dijual ke pengepul barang bekas dan diolah kembali dalam pabrik menjadi bahan baru. Oleh beberapa pengrajin keleng bekas tersebut diolah menjadi barang berguna untuk keperluan rumah tangga parutan kelapa, cikrak, saringan penggorengan, asbak, wajan cangkir dan sebagainya. Masih banyak yang bisa diperbuat untuk mengurangi sampah atau limbah kaleng dilingkungan sekitar. Tentu hal ini bukan hal mudah. Sikap konsumtif yang melanda generasi saat ini dengan makanan dan minuman kaleng sebagai sebuah gaya hidup upaya menumbuhkan keasadran untuk mengolah dan

\section{METODOLOGI PENELITIAN}

\subsection{Lokasi Penelitian dan Lokasi Pengambilan Material}

Salah satu hal penting yang perlu diperhatikan dalam melakukan penelitian adalah penentuan atau pemilihan lokasi pengambilan material untuk pembuatan benda uji. Dalam pemilihan lokasi pengambilan benda uji kita harus memperhatikan tempat pengambilan benda uji agar mendapatkan agregat yang bagus sesuai dengan keinginan kita. Penelitian ini akan diadakan di laboratorium Teknik Sipil Universitas Krsten Indonesia Toraja, Kabupaten Toraja Utara, penelitian ini dilakukan di laboratorium Teknik Sipil Universitas Kristen Indonesia Toraja karena fasilitas laboratorium sudah memadai serta jarak yang cukup dekat karena berada di kampus sendiri. Dalam penelitian ini, penulis memilih lokasi pengambilan material yaitu agregat halus yang di ambil dari Tapparan. Tapparan berada kurang lebih $12 \mathrm{~km}$ dari Makale, Kabupaten Tana Toraja. Lokasi ini dipilih sebagai lokasi pengambilan agregat halus untuk pembuatan benda uji karena jenis dan jumlah material yang cukup banyak, sarana transportasi ke lokasi tersebut memadai serta merupakaan lokasi penambangan agregat halus bagi masyarakat umum. Daerah Tapparan merupakan daerah yang terletak di Kecamatan Rembon, Kabupaten Tana Toraja dengan koordinat geografis berada pada $3^{\circ} 5^{\prime} 9^{\prime \prime}$ LS dan 119'48'3" BT. Adapun batas wilayah

Tapparan (Rembon) yaitu:

- Sebelah Utara : Kecamatan Rantetayo

- Sebelah Timur : Kecamatan Makale Selatan

- Sebelah Selatan : Kecamatan Makale Selatan

- Sebelah Barat : Kecamatan Malimbong Balepe, Kecamatan Bonggakaradeng

\subsection{Tahap dan Prosedur Penelitian}

Sebagai penelitian ilmiah maka penelitian harus dilaksanakan dalam sistematika atau urutan kerja yang jelas dan teratur. Pelaksanaan penelitian ini dibagi menjadi tahap-tahap sebagai berikut :

1. Tahap I

Tahap I adalah tahap persiapan. Pada tahap ini semua bahan dan peralatan yang akan digunakan dalam penelitian disiapkan terlebih dahulu sehingga penelitian yang akan dilakukan dapat berjalan dengan lancar.

2. Tahap II

Tahap II adalah Tahap pengujian karakteristik. Pada tahap ini dilakukan penelitian terhadap agregat kasar dan agregat halus. Hal ini dilakukan untuk mengetahui sifat dan karakteristik bahan yang akan digunakan, selain itu juga untuk mengetahui apakah agregat tersebut memenuhi persyaratan atau tidak. Hasil dari pengujian ini nantinya akan digunakan sebagai data rencana.

\section{Tahap III}

Tahap III adalah tahap pembuatan benda uji.Pada tahap ini dilakukan analisa rancangan campuran aspal, setelah didapatkan proporsi dari bahan yang akan digunakan dalam campuran aspal tersebut, dilakukan pembuatan benda uji dilanjutkan 


\section{DynamicSainT}

Jilid. IV No. 2., Oktober 2019

dengan pengujian.Setelah didapatkan hasil campuran aspal (mix design), apabila tidak memenuhi spesifikasi maka kita kembali keperencanaan campuran aspal (mix design) selanjutnya mengulang prosedur pembuatan benda uji dan pengujian marshall, dan jika sudah memenuhi spesifikasi maka akan didapatkan hasil dari pengujian aspal beton untuk menghitung temperatur.

\section{Tahap IV}

Tahap IV adalah tahap analisis data. Pada tahap ini data-data yang diperoleh dari hasil pengujian dianalisa dengan metode statistik dengan bantuan program microsoft excel untuk mendapatkan nilai karakteristik marshall campuran aspal dingin selanjutnya dengan penentuan kadar aspal optimum (KAO) serta penentuan nilai marshall immersion campuran aspal beton.

\section{Tahap V}

Tahap V adalah tahap pengambilan kesimpulan. Pada tahap ini data campuran aspal dingin yang telah dianalisa pada tahap sebelumnya kemudian dibuatkan kesimpulan dan saran yang berhubungan dengan tujuan penelitian

\subsection{Pengujian Berat Jenis aluminium yang akan di campurkan pada lapisan aspal beton (Kemasan minuman)}

Pemeriksaan berat jenis bahan ini

(Kemasan minuman) dimaksudkan untuk menentukan berat jenis yang digunakan sebagai bahan tambah terhadap karakteristik pada campuran lapisan aspal dingin dengan variasi $1 \%, 2 \%$ dan 3\% kemudian dihitung kedalam gram (Gr) dengan menggunakan rumus ketentuan sesuai dengan standar spesifikasi Bina Marga, Lalu ditimbang dengan menggunakan timbangan hidrolik

\subsection{Pembuatan Benda Uji}

Benda uji yang digunakan dalam pengujian lapisan aspal ini ada 15 buah untuk lapisan aspal beton yang bervariasi $4,5 \%$,
$5,0 \%, \quad 5,5 \%, 6,0 \%$, dan $6,5 \%$, untuk memperoleh kadar aspal optimum dalam campuran. Selanjutnya mengacu pada spesifikasi bahan tambah pada lapisan aspal dingin yaitu 9 buah dengan variasi $1 \%, 2 \%$, dan 3\% untuk memperoleh kadar aspal dengan campuran aluminium yang dihitung menggunakan rumus ketentuan sesuai standar spesifikasi Bina Marga dan di timbang menggunakan timbangan hidrolik. Berikut lankah-langkah dalam pembuatan benda uji dengan menggunakan (Kemasan Minuman) :

1. Timbang agregat sesuai dengan rumus spesifikasi Bina Marga yang sudah di tentukan.

2. Timbang aspal sesuai dengan variasi masingmasing yang sudah di tentukan.

3. Timbang kemasan minuman yang sudah di gunting menjadi kecil sesuai dengan variasi masing-masing kemudian campurkan dengan agregat yang sudah di timbang lalu dipanaskan di atas suhu $200^{\circ} \mathrm{C}$ dan tunggu hingga aluminium menjadi lentur, setelah proses selesai lalu di dinginkan kembali.

4. Campurkan aspal dengan agregat yang sudah tercampur kemasan minuman lalu di aduk sampai menyatu.

5. Tumbuk dengan menggunakan alat penumbuk aspal.

\subsection{Pengujian Marshall}

Untuk menentukan kadar aspal optimum benda uji harus memenuhi seluruh karakteristik marshall (stabilitas, flow, VIM, VFB dan VMA) sesuai standar Bina Marga. Adapun langkah-langkah kerja dari pengujian Marshall yaitu :

1. Rendam benda uji dalam bak perendaman (water bath) selama 30-40 menit dengan suhu tetap $(60 \pm 1)^{0} \mathrm{C}$.

2. Keluarkan benda uji dari bak perendaman dan letakkan ke dalam segmen bawah kepala penekan dengan catatan bahwa waktu yang diperlukan dari saat diangkatnya benda uji dari bak perendaman sampai tercapainya beban 


\section{DynamicSainT}

Jilid. IV No. 2., Oktober 2019

maksimum tidak boleh melebihi 30 detik.

3. Pasang segmen atas di atas benda uji dan letakkan keseluruhannya dalam mesin penguji.

4. Pasang arloji pengukuran pelelehan (flow) pada kedudukannya di atas salah satu batang penuntun dan atur kedudukan jarum penunjuk pada angka nol, sementara selubung tangki arloji (sleeve) dipegang teguh terhadap segmen atas kepala penekan.

5. Naikkan kepala penekan beserta benda ujinya sehingga menyentuh alas cincin penguji, sebelum pembebanan dilakukan.

6. Berikan pembebanan pada benda uji sampai pembebanan maksimum tercapai seperti yang ditunjukkan oleh jarum arloji.

7. Catat nilai pelelehan (flow) yang ditunjukkan oleh jarum arloji pengukur pelelehan pada saat pembebanan maksimum tercapai.

\subsection{Tahapan Penelitian}

1. Mengumpulkan Informasi Lokasi Penelitian Pada tahapan ini, peneliti menumpulkan informasi mengenai lokasi penelitian melalui survey pendahuluan serta wawancara dengan penduduk sekitar. Informasi yang sangat dibutuhkan pada tahapan ini adalah tentang intensitas kabut pada lokasi penelitian serta kondisi cuaca lainnya seperti suhu, arah dan kecepatan angin serta curah hujan. Melalui infomasi ini dapat ditentukan lokasi yang tepat untuk penelitian.

2. Instalasi Alat Setelah titik lokasi penelitian ditentukan, kemudian alat dan bahan dimobilisasi ke lokasi penelitian untuk kemudian dipasang sesuai dengan desain yang direncanakan. Setelah alat terpasang, dilakukan uji coba terhadap alat penelitian agar berfungsi sesuai rencana sehingga tidak ada faktorfaktor lain yang dapat mempengaruhi data.

3. Pengamatan Setelah alat penelitian telah berfungsi sebagaimana mestinya, kemudian pengamatan mulai dilakukan dengan mencatat setiap data yang dibutuhkan dalam analisis nantinya. Pegamatan dilakukan selama kurang lebih 3 bulan pada musim kemarau/ kering. Adapun jika terjadi hujan, maka data pada hari tersebut tidak dimasukkan dalam inventarisasi data. Semua faktor yang mempengaruhi hasil pengamatan selama penelitian juga dicatat sebagai bahan analisis pada tahapan berikutnya.

4. Analisis Data Data yang terkumpul kemudian dianalisis untuk mendapatkan tujuan dari penelitian ini. Data yang ada disajikan dalam bentuk tabel dan diagram dengan interval waktu tertentu. Kemudian disusun sebuah kesimpulan yang dapat diperoleh dari penelitian ini.

\section{HASIL DAN PEMBAHASAN}

\subsection{Hasil Pengujian Karakteristik Bahan}

\subsubsection{Hasil Pengujian Karakteristik Agregat \\ Bahan agregat yang digunakan dalam} penelitian ini yaitu kerikil sebagai agregat kasar, pasir sebagai agregat halus yang berasal dari sungai maulu serta semen bosowa sebagai bahan pengisi (filler) dengan pengujian berdasarkan standar spesifikasi umum Bina Marga 2010 revisi.

\section{Agregat Kasar}

Hasil pengujian karakteristik agregat kasar sesuai dengan metode pengujian yang dipakai serta standar spesifikasi yang disyaratkan yaitu pada tabel 1 . sebagai berikut: 


\section{DynamicSainT}

Jilid. IV No. 2., Oktober 2019

Tabel 1. Karakteristik agregat kasar

\begin{tabular}{|c|c|c|c|c|}
\hline No & $\begin{array}{l}\text { Jenis } \\
\text { Pengujian }\end{array}$ & Metode & Hasil & Spesifikasi \\
\hline 1 & $\begin{array}{l}\text { Berat } \\
\text { jeniscurah } \\
\text { (bulk) }\end{array}$ & $\begin{array}{l}\text { SNI 1969: } \\
2008\end{array}$ & 2.7 & Min. 2.5 \\
\hline 2 & $\begin{array}{l}\text { Berat jenis } \\
\text { SSD }\end{array}$ & $\begin{array}{l}\text { SNI 1969: } \\
2008\end{array}$ & 2.72 & Min. 2.5 \\
\hline 3 & $\begin{array}{l}\text { Berat jenis } \\
\text { semu } \\
\text { (apparent) }\end{array}$ & $\begin{array}{l}\text { SNI } 1969 \text { : } \\
2008\end{array}$ & 2.75 & Min. 2,5 \\
\hline 4 & $\begin{array}{l}\text { Penyerapan } \\
\text { (absorption) }\end{array}$ & $\begin{array}{l}\text { SNI 1969: } \\
2008\end{array}$ & 0.68 & Maks. 3 \\
\hline 5 & $\begin{array}{l}\text { Keausan } \\
\text { Agregat (los } \\
\text { Angeles })\end{array}$ & $\begin{array}{l}\text { SNI } 2417: \\
2008\end{array}$ & 26.25 & Maks. 40 \\
\hline 6 & $\begin{array}{l}\text { Ketahanan } \\
\text { agregat } \\
\text { terhadap } \\
\text { tumbukan }(i \\
\text { mpactTest })\end{array}$ & $\begin{array}{l}\text { SNI 03- } \\
4426- \\
1997\end{array}$ & 12.74 & Maks. 30 \\
\hline 7 & $\begin{array}{l}\text { Kadar } \\
\text { lumpur dan } \\
\text { lempung }\end{array}$ & $\begin{array}{l}\text { SNI 03- } \\
4141- \\
1996\end{array}$ & 0.85 & Maks. 1 \\
\hline
\end{tabular}

Sumber : Hasil Pengujian Laboratorium Teknik Sipil UKI Toraja, 2020

\section{Agregat Halus}

Hasil pengujian karakteristik pasir sebagai agregat halus yang berasal dari Sungai Maulu sesuai dengan metode pengujian yang dipakai serta standar spesifikasi yang disyaratkan yaitu pada table 2. sebagai berikut:

Tabel 2. Karakteristik agregat halus

\begin{tabular}{|c|l|c|c|l|}
\hline No & $\begin{array}{l}\text { Jenis } \\
\text { Pengujian }\end{array}$ & Metode & Hasil & Spesifikasi \\
\hline 1 & $\begin{array}{l}\text { Berat } \\
\text { jeniscurah( } \\
\text { bulk })\end{array}$ & $\begin{array}{c}\text { SNI 1969: } \\
2008\end{array}$ & 2.63 & Min. 2.5 \\
\hline 2 & $\begin{array}{l}\text { Berat jenis } \\
\text { SSD }\end{array}$ & $\begin{array}{c}\text { SNI 1969: } \\
2008\end{array}$ & 2.7 & Min. 2.5 \\
\hline 3 & $\begin{array}{l}\text { Berat jenis } \\
\text { semu } \\
\text { (apparent) }\end{array}$ & $\begin{array}{c}\text { SNI 1969: } \\
2008\end{array}$ & 2.83 & Min. 2,5 \\
\hline 4 & $\begin{array}{l}\text { Penyerapan } \\
\text { (absorption) })\end{array}$ & $\begin{array}{c}\text { SNI 1969: } \\
2008\end{array}$ & 2.67 & Maks. 3 \\
\hline 5 & $\begin{array}{l}\text { Kadar lumpur } \\
\text { dan lempung }\end{array}$ & $\begin{array}{c}\text { SNI 03-4141- } \\
1996\end{array}$ & 0.9 & Maks. 1 \\
\hline
\end{tabular}

Sumber : Hasil Pengujian Laboratorium Teknik Sipil UKI Toraja, 2020

\subsubsection{Analisa Gradasi Agregat Gabungan AC-WC \\ Analisa Gradasi Agregat Gabungan} AC-WC Gradasi agregat gabungan dalam penelitian ini mengacu pada campuran ACWC yang ditunjukkan dalam persen terhadap berat agregat yang memenuhi jarak gradasi agregat gabungan terhadap batas-batas toleransi berdasarkan spesifikasi umum Bina Marga 2010 revisi 3. Untuk hasil analisa gradasi agregat gabungan batu pecah PT Sabar Jaya sebagai agregat kasar dengan berat bahan 1000 gram dan pasir Tapparan sebagai agregat halus dengan berat bahan 1000 gram dapat disajikan pada tabel 3. sebagai berikut

Tabel 3. Analisa gradasi agregat gabungan ACWC

\begin{tabular}{|c|c|c|c|c|c|c|c|}
\hline \multicolumn{2}{|c|}{$\begin{array}{c}\text { Ukuran } \\
\text { Saringan }\end{array}$} & \multirow{2}{*}{$\begin{array}{c}\text { Berat } \\
\text { Saringan (gr) }\end{array}$} & \multirow{2}{*}{\begin{tabular}{|c|} 
Berat \\
Saringan + \\
Tertahan \\
(gr) \\
\end{tabular}} & \multirow{2}{*}{$\begin{array}{c}\text { Berat } \\
\text { Tertahan } \\
\text { (gr) }\end{array}$} & \multirow{2}{*}{$\begin{array}{c}\sum \text { Berat } \\
\text { Tertahan } \\
\text { (gr) }\end{array}$} & \multirow{2}{*}{$\begin{array}{c}\text { Persen } \\
\text { Total } \\
\text { Tertahan } \\
(\%) \\
\end{array}$} & \multirow{2}{*}{$\begin{array}{r}\text { Persen } \\
\text { Lolos (\%) }\end{array}$} \\
\hline $\mathrm{Mm}$ & Inch & & & & & & \\
\hline 25 & 1" & 495 & 495 & 0 & 0 & 0 & 100 \\
\hline 19 & $3 / 4 "$ & 521 & 521 & 0 & 0 & 0 & 100.00 \\
\hline 12.5 & $1 / 2^{\prime \prime}$ & 457 & 621 & 164 & 164 & 8 & 91.80 \\
\hline 9.5 & $3 / 8^{\prime \prime}$ & 478 & 742 & 264 & 428 & 21.40 & 78.60 \\
\hline 4.75 & No. 4 & 462 & 847 & 385 & 813 & 40.65 & 59.35 \\
\hline 2.36 & No. 8 & 299 & 582 & 283 & 1096 & 54.80 & 45.2 \\
\hline 1.18 & No. 16 & 319 & 480 & 161 & 1257 & 62.85 & 37.15 \\
\hline 0.600 & No. 30 & 437 & 628 & 191 & 1448 & 72.40 & 27.60 \\
\hline 0.300 & No. 50 & 310 & 481 & 171 & 1619 & 80.95 & 19.05 \\
\hline 0.150 & No. 100 & 281 & 430 & 149 & 1768 & 87.25 & 12.75 \\
\hline 0.075 & No. 200 & 317 & 424 & 107 & 1934 & 94.40 & 5.60 \\
\hline \multicolumn{2}{|c|}{ Pan } & 450 & 516 & 66 & 2000 & 100 & 0 \\
\hline
\end{tabular}

\subsection{Analisa Rancangan Campuran}

Komposisi rancangan dibagi menjadi tiga fraksi yaitu fraksi agregat kasar, fraksi agregat halus dan fraksi bahan pengisi (filler). Total agregat yang akan digunakan dalam rancangan campuran adalah 1200 gram dengan komposisi rancangan seperti pada tabel 4. sebagai berikut:

Tabel 4. Rancangan Komposisi Campuran

\begin{tabular}{|c|c|c|c|c|c|c|c|c|}
\hline \multicolumn{2}{|c|}{$\begin{array}{l}\text { UKURAN } \\
\text { SARINGAN }\end{array}$} & \multicolumn{2}{|c|}{$\begin{array}{c}\text { PERSENTASE } \\
\text { LOLOS }(\%)\end{array}$} & \multirow{2}{*}{$\begin{array}{c}\text { JUMLAH } \\
\text { TERTAHAN } \\
(\%)\end{array}$} & \multicolumn{2}{|c|}{$\begin{array}{c}\text { JUMLAH BAHAN } \\
\text { MENURUT } \\
\text { SPESIFIIKASI } \\
\end{array}$} & \multicolumn{2}{|c|}{$\begin{array}{l}\text { JUMLAH } \\
\text { AGREGAT }\end{array}$} \\
\hline ASTM & $(\mathrm{mm})$ & KISARAN & TARGET & & $\begin{array}{c}\text { TERTAHAN } \\
(\%)\end{array}$ & $\underset{\text { (gr) }}{\text { TERTAHAN }}$ & (Gr) & $\%$ \\
\hline 1" & 25 & 100 & 100 & 0 & 0 & 0 & \multirow{5}{*}{502.6} & \multirow{5}{*}{41.9} \\
\hline 3/4" & 19 & 100 & 100 & 0 & 0 & 0 & & \\
\hline $1 "$ & 12.5 & $90-100$ & 91.55 & 8 & 8 & 101.39 & & \\
\hline $38^{\prime \prime}$ & 9.5 & $72-90$ & 77.95 & 22.05 & 13.60 & 163.21 & & \\
\hline No4 & 4.75 & $54-69$ & 58.11 & 41.89 & 19.84 & 238.02 & & \\
\hline No8 & 2.36 & $39.1-53$ & 43.53 & 56.47 & 14.58 & 174.96 & \multirow{6}{*}{630.2} & \multirow{6}{*}{52.5} \\
\hline No 16 & 1.18 & $31.6-40$ & 35.24 & 64.76 & 8.29 & 99.54 & & \\
\hline № 30 & 0.600 & $23.1-30$ & 25.40 & 74.60 & 9.84 & 118.08 & & \\
\hline № 50 & 0.300 & $15.5-22$ & 16.59 & 83.41 & 8.81 & 105.72 & & \\
\hline № 100 & 0.150 & $9-15$ & 12.75 & 87.25 & 3.84 & 46.07 & & \\
\hline № 200 & 0.075 & $4-10$ & 5.60 & 94.40 & 7.15 & 85.80 & & \\
\hline \multicolumn{2}{|c|}{ PAN } & 0 & 0 & 100 & 5.60 & 67.20 & 67.20 & 5.60 \\
\hline \multicolumn{5}{|c|}{ Jumlah } & 100 & 1200 & 1200 & 100 \\
\hline
\end{tabular}




\section{DynamicSainT}

Jilid. IV No. 2., Oktober 2019

1) Komposisi Agregrat Kasar

$=\frac{\text { Berat } \text { Total Tertahan saringan }(3 / 4 "-N o .4)}{\text { Berat Total Agregat }} \times 100 \%$

$=\frac{101.39+163.21+238.02}{1200} \times 100 \%$

$=41.9 \%$

2) Komposisi Agregrat Halus

$=\frac{\text { Berat Total Tertahan saringan (No.8-No.200) }}{1200} \times 100 \%$

$=\frac{174.96+99.54+118.08+105.72+46.07+85.80}{1200} \times 100 \%$

$=\mathbf{5 2 . 5 \%}$

3) Komposisi Bahan Pengisi (filler)

$=\frac{P A N}{\text { Berat Total Agregat }} \times 100 \%$

$=\frac{67.20}{1200} \times 100 \%$

$\mathbf{5} \mathbf{5 . 6 0 \%}$

\subsection{Rancangan Kadar Aspal Dalam Campuran}

Untuk mendapatkan nilai Kadar Aspal Optimum (KAO) untuk campuran AC-WC dapat dihitung dari kadar aspal rencana dengan menggunakan rumus :

$$
\begin{gathered}
\mathrm{Pb}=0,035(\% \mathrm{CA})+0,045(\% \mathrm{FA})+0,18(\% \mathrm{FF})+ \\
\mathrm{K}
\end{gathered}
$$

Dimana :

$\mathrm{Pb}=$ Kadar aspal perkiraan

$\mathrm{CA}=$ Agregat kasar tertahan pada saringan no. 4

FA = Agregat halus lolos saringan no.4 tertahan saringan no. 200

$\mathrm{FF}=$ Filler (lolos saringan no.200)

$\mathrm{K}=\operatorname{Konstanta}$ (nilai $0.5-1.0$ untuk AC)

Jadi untuk

$$
\begin{aligned}
\mathrm{Pb}= & 0.035(41.9 \%)+0.045(52.5 \%)+ \\
& 0.18(5.6 \%)+0.7
\end{aligned}
$$$$
\mathbf{P b}=\mathbf{5 . 5 \%}
$$

Kadar aspal yang digunakan dalam pengujian Marshall :

Cara menentukan kadar aspal yang akan digunakan dalam rancangan campuran dua nilai kadar aspal dibawah dari nilai $\mathrm{Pb}$ dan dua nilai kadar aspal diatas dari nilai $\mathrm{Pb}$ dengan masing-masing nilai selisih 0,5 .
$\mathrm{Pb}-1, \mathrm{~Pb}-0.5, \mathrm{~Pb}, \mathrm{~Pb}+0.5, \mathrm{~Pb}+1=(4.5 \%, 5 \%$, $5.5 \%, 6 \%, 6.5 \%$ )

Kadar aspal dalam campuran dapat diperoleh melalui perhitungan sebagai berikut:

$$
\begin{aligned}
\text { Berat Aspal } & =\frac{4.5 \%}{100-4.5 \%} \times 1200 G r \\
& =\mathbf{5 7} \mathbf{g r}
\end{aligned}
$$

Tabel 5. Proporsi Aspeal dalam Campuran

\begin{tabular}{|c|c|c|}
\hline No. & Kadar Aspal (\%) & Berat Aspal (gr) \\
\hline 1 & $4.5 \%$ & 57 \\
\hline 2 & $5 \%$ & 63 \\
\hline 3 & $5.5 \%$ & 70 \\
\hline 4 & $6 \%$ & 77 \\
\hline 5 & $6.5 \%$ & 83 \\
\hline
\end{tabular}

Tabel 6. Proporsi Aspal dalam Campuran

\begin{tabular}{|c|c|c|}
\hline No. & Kadar Aspal (\%) & $\begin{array}{c}\text { Berat Bahan } \\
\text { Tambah }(\mathbf{g r})\end{array}$ \\
\hline 1 & $1 \%$ & 12 \\
\hline 2 & $2 \%$ & 24 \\
\hline 3 & $3 \%$ & 36 \\
\hline
\end{tabular}

\subsection{Hasil Pengujian Karakteristik Marshall \\ Pengujian karakteristik Marshall} berdasarkan pengujian di laboratorium pada kadar aspal 4.5\%, 5\%, 5.5\%, 6\% dan 6.5\% yang masing-masing 3 sampel benda uji dengan jumlah total sampel 15 benda uji dan untuk bahan tambah terdiri dari 9 benda uji pada variasi $5,5 \%$ yang telah mencapai kadar aspal optimum.

\subsection{Hasil Pengujian Karakteristik Marshall Aspal Beton (AC-WC) \\ Dari pengujian laboratorium yang} dilakukan pada setiap sampel benda uji untuk setiap variasi kadar aspal, maka diperoleh hasil karakteristik marshall rata-rata campuran AC-WC seperti pada tabel 7 . sebagai berikut :

Tabel 7. Hasil Pengujian Karakteristik Marshall Rata-rat Campuran AC-WC Pengujian Marshall Campuran AC-WC (2x75)Tumbukan 


\section{DynamicSainT}

Jilid. IV No. 2., Oktober 2019

\begin{tabular}{|c|c|c|c|c|c|c|}
\hline $\begin{array}{c}\text { Variasi } \\
\text { Kadar } \\
\text { Aspal(\%) }\end{array}$ & $\begin{array}{c}\text { VIM } \\
(\%)\end{array}$ & $\begin{array}{c}\text { VFB } \\
(\%)\end{array}$ & $\begin{array}{c}\text { VMA } \\
(\%)\end{array}$ & $\begin{array}{c}\text { Stabilitas } \\
(\mathbf{k g})\end{array}$ & $\begin{array}{c}\text { Flow } \\
(\mathbf{m m})\end{array}$ & $\begin{array}{c}\text { MQ } \\
(\mathbf{k g} / \mathbf{m m})\end{array}$ \\
\hline 4.5 & 5.33 & 63.03 & 14.28 & 1076.7 & 2.63 & 430.57 \\
\hline 5 & 4.94 & 67.22 & 15.02 & 1041.5 & 2.91 & 373.47 \\
\hline 5.5 & 4.51 & 71.42 & 15.71 & 1008.5 & 3.27 & 309.21 \\
\hline 6 & 4.2 & 74.61 & 16.5 & 958.73 & 3.47 & 277.45 \\
\hline 6.5 & 3.78 & 78.1 & 17.19 & 945.43 & 4.13 & 229.29 \\
\hline
\end{tabular}

\subsection{Pembahasan Hasil Pengujian \\ Karakteristik Marshall Dengan \\ Penambahan Aluminium Pada \\ Campuran Aspal Beton (AC-WC) \\ Dari hasil pengujian laboratorium} didapatkan hasil Pengujian dengan menggukan Kadar Aspal Optimum (KAO) pada tabel 9. sebagai berikut :

Tabel 9. Hasil Pengujian Penambahan Aluminium dengan menggukan Kadar Aspal Campuran AC-WC Bahan Tambah Dengan Variasi KAO

\begin{tabular}{|c|c|c|c|c|c|c|}
\hline \multicolumn{7}{|c|}{ Pengujian Marshall CampuranAC-WC(2x75)Tumbukan } \\
\hline $\begin{array}{c}\text { Variasi } \\
\text { Kadar } \\
\text { Aspal } \\
(\%)\end{array}$ & $\begin{array}{c}\text { VIM } \\
(\%)\end{array}$ & $\begin{array}{c}\text { VFA } \\
(\%)\end{array}$ & $\begin{array}{c}\text { VMA } \\
(\%)\end{array}$ & $\begin{array}{c}\text { Stabilit as } \\
(\mathbf{k g})\end{array}$ & $\begin{array}{c}\text { Flo } \\
\mathbf{w} \\
(\mathbf{m m})\end{array}$ & $\begin{array}{c}\text { MQ } \\
(\mathbf{k g} / \mathbf{m m})\end{array}$ \\
\hline 5.5 & 4.26 & 72.56 & 15.59 & 672.66 & 5.8 & 116.53 \\
\hline
\end{tabular}

\subsection{Pembahasan Hasil Pengujian Karakteristik Marshall. \\ Pembahasan hasil pengujian} karakteristik marshall dalam penelitian ini sesuai dengan ketentuan sifat-sifat campuran yaitu :

1. VIM/Voids In Mix (rongga dalam campuran) adalah volume rongga udara diantara partikel agregat yang terselimuti aspal

2. VFB/Void Filled with Bintumen (rongga terisi aspal) adalah persen rongga yang terdapat diantara partikel agregat (VMA) yang terisi oleh aspal, tidak termasuk aspal yang diserap oleh agregat.

3. $\mathrm{VMA} /$ Void in Mineral Aggregate (rongga dalam agregat) adalah ruang rongga diantara partikel agregat pada suatu perkerasan termasuk rongga udara dan volume aspal efektif (tidak termasuk volume aspal yang diserap agregat)

4. Stabilitas adalah kemampuan maksimum aspal beton padat menerima beban sampai terjadi kelelehan plastis.

5. Flow (kelelehan) adalah besarnya perubahan bentuk plastis dari aspal padat beton akibat adanya beban sampai batas keruntuhan

6. MQ / Marshall Quotient adalah hasil bagi dari stabilitas dengan kelelehan. Optimum (KAO)

\begin{tabular}{|l|c|c|c|l|}
\hline \multicolumn{1}{|c|}{ Jenis Pengujian } & Nilai & Satuan & $\begin{array}{c}\text { Spesifikasi } \\
\text { BinaMarga }\end{array}$ & Keterangan \\
\hline $\begin{array}{l}\text { Void In The Mix } \\
\text { (VIM) }\end{array}$ & 4.26 & $\%$ & $\begin{array}{l}\text { Min. 3.0\%- } \\
\text { Maks. 5.0\% }\end{array}$ & Memenuhi \\
\hline $\begin{array}{l}\text { Void Filler In } \\
\text { Bitument (VFB) }\end{array}$ & 72.56 & $\%$ & Min. 65\% & Memenuhi \\
\hline $\begin{array}{l}\text { Void In Mineral } \\
\text { Aggregate (VMA) }\end{array}$ & 15.59 & $\%$ & Min. 15\% & Memenuhi \\
\hline Stabilitas & 672.66 & $\mathrm{~kg}$ & Min. 800 & $\begin{array}{l}\text { Tidak } \\
\text { Memenuhi }\end{array}$ \\
\hline Flow & 5.8 & $\mathrm{~mm}$ & $\begin{array}{l}\text { Min. . - } \\
\text { Maks. 4.0 }\end{array}$ & $\begin{array}{l}\text { Tidak } \\
\text { Memenuhi }\end{array}$ \\
\hline $\begin{array}{l}\text { Marshall Quotient } \\
\text { (MQ) }\end{array}$ & 116.53 & $\mathrm{~kg} / \mathrm{mm}$ & Min. 250 & $\begin{array}{l}\text { Tidak } \\
\text { Memenuhi }\end{array}$ \\
\hline
\end{tabular}

\subsection{Penentuan Kadar Aspal Optimum} (KAO)

a. Penentuan Kadar Aspal Optimum (KAO) pada Campuran Aspal Beton (AC-WC)

Kadar aspal optimum yaitu jumlah aspal yang digunakan dalam campuran agar tercapai persyaratan nilai Stabilitas, Flow, VMA, VFA, VIM dan Marshall Question seperti pada gambar 4.10. sebagai berikut :

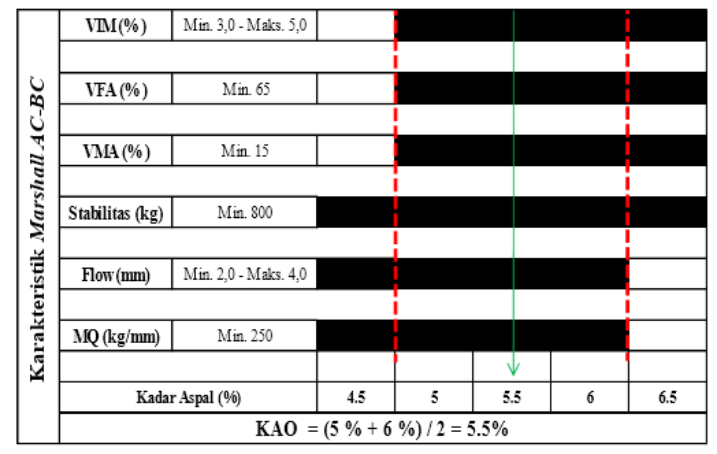

Gambar 4.10. Diagram Penentuan KAO pada Campuran Aspal Beton(AC-WC) 


\section{DynamicSainT}

Jilid. IV No. 2., Oktober 2019

1. Nilai VIM (Void In The Mix) memenuhi syarat pada kadar aspal $5 \%$ sampai $6,5 \%$

2. Nilai VFA (Void Filled with Aspalt) memenuhi syarat pada kadar aspal 5\% sampai $6,5 \%$

3. Nilai VMA (Void in Mineral Aggregate) memenuhi syarat pada kadar aspal 5\% sampai $6,5 \%$

4. Nilai Stabilitas memenuhi syarat pada kadar aspal 4,5\% sampai 6,5\%

5. Nilai Kelehan (Flow) memenuhi syarat pada kadar aspal $4,5 \%$ sampai $6 \%$

6. Nilai MQ (Marshall Quotient) memenuhi syarat pada kadar aspal $4,5 \%$ sampai $6 \%$.

\subsection{Analisa Hasil Pengujian Marshall Immersion (KAO) \\ Marshall Immersion adalah salah satu}

pengujian untuk melihat durabilitas (ketahanan terhadap beban dan pengaruh suhu) atau keawetan suatu campuran, hasil dari pengujian ini adalah rasio stabilitas. Rasio tersebut dibandingkan stabilitas dari benda uji marshall setelah direndam dalam water bath dengan suhu $60^{\circ} \mathrm{C}$ selama 24 jam terhadap stabilitas benda uji marshall dengan 30 menit yang biasa disebut Indeks Perendaman (IP) atau Indeks Kekuatan Sisa (IKS)

Indeks Perendaman (Marshall Immersion) dari campuran Aspal Beton (ACWC) selama 30 menit adalah 945,45 dan selama 24 jam adalah 943,14 dengan perhitungan sebagai berikut :

$$
\begin{gathered}
\mathrm{IP}=\frac{\text { Stabilitas Marshall Immertion }}{\text { Stabilitas Marshall Standar }} \times 100 \% \\
\begin{aligned}
\mathrm{IP} & =943,14945,45 \times 100 \% \\
& =99,756 \%
\end{aligned}
\end{gathered}
$$

Hasil Pengujian Marshall Immersion diperoleh indek perendaman sebesar $99,756 \%$. Nilai indeks perendaman ini telah memenuhi standar spesifikasi Bina Marga yaitu $\geq 90 \%$.

\section{KESIMPULAN DAN SARAN}

\subsection{Kesimpulan}

Berdasarkan hasil Pengujian

Laboratorium tentang Pengaruh Penambahan Limbah Aluminium Kemasan Minuman Terhadap Karakteristik Lapisan Aspal Beton diperoleh kesimpulan sebagai berikut :

1. Nilai karakteristik aspal beton yang diperoleh berdasarkan pengujian marshall pada kondisi Kadar Aspal Optimum (KAO). Untuk nilai VIM yaitu $4,71 \%$, nilai VMA $15,88 \%$, nilai $\mathrm{VFB}$ $70,46 \%$, nilai Stabilitas $943,14 \mathrm{~kg}$, nilai Flow $3.3 \mathrm{~mm}$, dan Marshall Quotient sebesar $283,49 \mathrm{~kg} / \mathrm{mm}$. Sedangkan untuk nilai VIM, VMA, VFB, Stabilitas dan Marshall Quotient tidak memenuhi standar sehingga nilai Kadar Aspal Optimum untuk penambahan aluminium pada variasi KAO tidak dapat dihitung. Hal ini disebabkan tidak tercapainya nilai standar minimal pada Stabilitas, Flow, dan Marshall Quotient.

\subsection{Saran}

Kinerja aspal beton mulai dari kadar aspal $4.5 \%$ sampai $6.5 \%$ (Niai > 800kg) telah memenuhi spesifikasi, demikian pula pada kondisi KAO. Sedangkan dengan penambahan limbah aluminium pada variasi KAO tidak memenuhi standar stabilitas Marshall yang ditetapkan oleh Bina Marga

\section{DAFTAR PUSTAKA}

1. Carlina, Serli. 2013. Pengaruh Variasi Temperatur Pemadatan Terhadap Nilai Stabilitas Marshall pada Laston AC-WC. Universitas Lampung. Bandar Lampung.

2. Direktorat Jendral Bina Marga, 2010. Spesifikasi Umum Bidang Jalan dan Jembatan Devisi 6 (revisi3) Perkerasan Beraspal. Pusat Litbang Jalan dan Jembatan Badan Penelitian dan Pengembangan. Bandung 


\section{DynamicSainT}

Jilid. IV No. 2., Oktober 2019

3. Hans Christian Oerstet. 1825. Penemuan aluminium.

4. Https://mfarofi.blogspot.com/2015/10/lim bah-kalengdan-pemanfaatan-limbah.html

5. Kementrian Pekerkerjaan Umum, 1992. Spesifikasi Umum 2010. Direktorat Jenderal Bina Marga Refisi 3. Jakarta.

6. Lestari, Tri. 2012. Studi Karakteristik Marshall Pada Campuran Asphalt Concrete-Binder Course (AC-BC) Bergradasi Kasar Akibat Perubahan Gradasi Agregat. Universitas Lampung. Bandar Lampung.

7. Nugroho, Ardiyanto., Aprilianto. Moh. Dwi, dan Aziz, E.A. 2015. Pengaruh Penambahan Polyethylene Terephthalate (PET) Dalam Campuran Aspal AC-WC Terhadap Nilai Stabilitas Marshall. Makalah Lomba CBR UNILA. UMY

8. Rangan, Parea Rusan; G.S., E.B., The effect of using sugar cane drops as a substitute some asphalt for $A C-B C$ and $A C$-WC concrete asphalt layer. Journal of advanced research in dynamical and control systems, volume 11 , issue 7 , 699706

9. SNI 03-1968-1990. (1990). Metode Pengujian Tentang Analisis Saringan Agregat Halus dan Kasar, Badan Standar Nasional, Jakarta.

10.SNI 06-2489-1991. (1991). Metode Pengujian Campuran Aspal dengan Alat Marshall, Badan Standar Nasional, Jakarta

11.Saodang, Hamirhan. 2005. Konstruksi Jalan Raya. Bandung. Nova. $243 \mathrm{Hlm}$.

12.Sukirman, Silvia.1999. Perkerasan Lentur Jalan Raya. Bandung.

13.Nova. Suprapto, 2004. Bahan dan Struktur Jalan Raya. Biro Penerbit KMTS FT UGM. Universitas Gadjah Mada. 